\title{
L'Ombre de ma mère
}

\author{
Suzanne Myre
}

We have all been influenced by the education given to us by our mothers. From birth to death, we wear the tattoo of its imprint; it guides our emotional, our adult lives. We carry the mother's gift of life and love, abandonment and pain. This story follows the trace left by what remains of the umbilical cord.

Visiblement, c'est madame Choquette, l'ancienne voisine, qui avait besoin de me parler de ma mère, plus que moi de l'entendre en parler. J'ai effacé le message sur mon répondeur en espérant l'effacer tout autant de ma mémoire, mais l'image de maman s'est mise à tournoyer dans mon esprit de manière insistante. Et comme j'ai l'anxiété facile, je l'ai revue, entre mes insomnies. Flamboyante, outrageusement belle. Choquante, surtout les dimanches, alors que la sobriété aurait été de meilleur goût. Les hommes allaient à l'église pour la voir, les femmes pinçaient leur mari pour qu'ils regardent ailleurs. Ma mère. Je me sentais si petite à côté d'elle, si insignifiante. Depuis qu'elle est morte, je le suis vraiment.

Alors j'ai rappelé la voisine, question de me donner bonne conscience, et parce que je suis curieuse; je ne connais pas grand-chose de ma mère. Madame Choquette avait appris le décès de maman par les journaux et trouvé mon numéro de téléphone dans les pages blanches. Facile, un nom comme le mien, il n'y en a qu'un. J'ai détesté longtemps ma mère pour avoir épousé un homme qui affichait un tel patronyme. Je l'ai détestée pour bien d'autres choses aussi. «J'aimerais vous parler de votre mère, je l'ai bien connue. Appelez-moi quand vous serez disposée à venir me voir » et ses coordonnées et blablabla et bip. Disposée. Qu'est-ce qu'une simple voisine pouvait tant avoir à $\mathrm{m}^{\prime}$ apprendre sur une mère qui est restée pour moi un mystère jusqu'à l'heure de sa mort? Je suis curieuse. Je suis allée. J'ai su.

« Elle faisait cela pour mettre à manger sur la table, tu sais, pas pour le plaisir. »

Tiens, comme moi.

«Les hommes aimaient être avec elle, pas juste pour la chose, mais 
pour parler. Elle pouvait les écouter aussi longtemps qu'ils avaient besoin de parler... »

Comme moi.

«...enfin, c'est ce que monsieur Dubreuil m'a dit... lui qui la "fréquentait" depuis que sa femme était décédée. Les hommes ont tellement de misère à être seuls. Elle les consolait. On la voyait partir le soir de chez vous, bien habillée, comme pour la messe. "

Ma mère. Ma maman qui allait se confesser à toutes les semaines, et sortait du confessionnal les yeux humides et la tête si inclinée que je craignais qu'elle se décroche de ses épaules et roule d'elle-même dans l'allée jusqu'à notre banc, me regarde et dise:

"Et toi, tu ne vas pas à confesse? " Je me sentais si coupable de ne pas y aller. $\mathrm{Il}$ aurait fallu que je m'invente des péchés. Je vivais comme une sainte. Moi.

« Je la jugeais, on la jugeait tous, en silence. Car on savait que depuis que ton père était mort, elle n'arrivait pas à joindre les deux bouts. Du moment qu'elle ne brisait pas de mariage, on pouvait le tolérer, dans le quartier. Elle brisait des solitudes, plutôt, la sienne tout autant. »

De qui elle parle là ...

"Puis, un jour, elle m'a demandé si elle pouvait étendre son linge sur ma corde. La sienne avait été emportée par une bourrasque, et elle n'avait personne pour l'aider à en remettre une autre. Curieux, elle qui était toujours avec des hommes, pas un pour l'aider. J'ai dit oui. Ça m'a tout pris, mais j'ai dit oui. J'ai toujours pensé qu'entre femmes, il fallait se soutenir."

Moi aussi, mais apparemment, ça ne marche pas comme ça. Marisa m'a piqué mon meilleur client, hier.

" Je l'ai invitée pour un thé, après qu'elle eut étendu son linge. J'étais gênée, des choses en dentelle, des bas transparents avec des motifs, des soutiens-gorges à falbalas, entremêlés de tes petites choses à toi. Tu étais si petite, tu es encore petite. Tu manges assez? "

Assez souvent. Pas toujours. Des fois. Quand j'arrive à joindre les deux bouts.

«On a parlé. Elle m'a tout dit. Elle m'a dit combien elle était honteuse, combien le prêtre était sévère avec elle, qu'il lui donnait tellement de chapelets à réciter pour sa punition qu'elle devait même les dire pendant qu'elle faisait la chose. Peut-être qu'au fond, ça 1'aidait à se sentir moins coupable. "

Coupable je l'ai été mon père, de blasphème. Une fois, un type m'a demandé de réciter des prières pendant qu'il était sur moi, ça l'excitait. 
«Sa plus grande peur était que tu ne l'apprennes. Mais elle me disait que tu ne parlais presque pas, que tu ne posais jamais de questions quand elle s'absentait et te laissait toute seule. Tu étais un peu jeune, je trouve, pour rester seule. "

Une petite sainte, c'est ça. Une fois, j'avais faim, pour quelque chose. J'ai fouillé dans ses tiroirs, je ne sais pas pourquoi, je pensais peut-être trouver une tablette de chocolat, une révélation, n'importe quoi. J'ai trouvé au lieu une photo de mon père, enfin, je pense bien que c'était lui. Il était laid, il ressemblait à certains de mes clients les plus tristes, mais je l'ai aimé. J'ai gardé la photo, elle ne s'est jamais aperçue de sa disparition.

«Tu étais jeune aussi lorsqu'elle est morte. »

Elle était jeune lorsqu'elle est morte. Trente-neuf ans, c'est un peu tôt pour laisser une petite fille de quinze ans derrière soi, maigre, transparente, à la recherche de son ombre, ou de celle d'une autre.

«Lorsque tu es partie vivre chez ta tante, j'ai pensé qu'un jour, il faudrait que tu saches. Crois-tu que j'ai bien fait? "

Dis-lui que oui. Dis-lui que ça ne fait aucune différence. N'importe quoi pour la rassurer. Mais ne lui dis surtout pas que l'insignifiance, ça s'attrape jeune et que ça grandit, avec l'âge. Et que maintenant plus que jamais, ça te suivra comme ton ombre. 